Journal of Molecular Genetics 1 (2-4): 29-34, 2009

ISSN: $2070-4267$

(C) Medwell Journals, 2009

\title{
Barcoding of Five Sturgeon Species in Iran
}

\author{
${ }^{1}$ Hassan Ghadirnejad, ${ }^{2,3}$ M.N. Siti Azizah, ${ }^{1}$ Aliakbar Salehi, \\ ${ }^{1}$ Kamran Aghili, ${ }^{2}$ Katialisa Kamaruddin, ${ }^{2}$ A.F. J. Jamsari and ${ }^{2}$ Lim Hong Chiun \\ ${ }^{1}$ Golestan Fisheries Research Center (GFRC), P.O. Box 139, Gorgan, Golestan Province, Iran \\ ${ }^{2}$ School of Biological Sciences, University Sains Malaysia, Penang, Malaysia \\ ${ }^{3}$ Centre for Marine and Coastal Studies, USM Penang, Malaysia
}

\begin{abstract}
The universal barcoding gene of Cytochrome Oxidase I (COI) was utilised for molecular characterisation of five sturgeon species found in the Iranian waters of the Caspian Sea. These were Acipenser gueldenstaedtii (Russian sturgeon), A. persicus (Persian sturgeon), A. stellatus (Stellate sturgeon), A. nudiventris (Spiny sturgeon) and Huso huso (Great sturgeon). An additional 10 sequences from the Genbank were included in the analysis, A. stellatus (AJ585050), H. huso (AY442351) A. baerii (FJ205560-FJ205563), A. fulvescens (EU524397), A. transmontanus (EU523891), A. medirostris (EU523885) and A. oxynrinchus (EU524401). The data was also analysed for phylogenetic insights among the studied species. The results confirmed the utility of this gene for molecular identification and revealed monophyly of three of the species; H. huso, A. nudiventris and A. stellatus. However, the status of $A$. gueldenstaedtii and A. persicus was unresolved with Genbank sequences of $A$. baerii (FJ205560-FJ205563) also clustering in the $A$. gueldenstaedtii-persicus complex as had been reported by previous researchers investigating other genes. Thus, the results provide further evidence of the polyphylic' nature of $A$. gueldenstaedtii. The data is also in agreement with several earlier reports that $H$. huso may not be a separate genus from Acipenser within the family Acipenserinae. The low internode bootstrap values at branch nodes did not allow for any phylogenetic inference among the Acipenser species to be deduced.
\end{abstract}

Key words: Genetic variation, barcoding, cytochrome oxidase I, sturgeon species, Iran

\section{INTRODUCTION}

The southern Caspian Sea of the Iranian waters is home to five sturgeon species namely Huso huso, Acipenser nudiventris, A. stellatus, A. gueldenstaedtii and $A$. persicus. As with many of their relatives in other regions, their populations are under serious threat (Rosenthal et al., 2006; Ghadimejad et al., 2008). This is mainly as a consequence of their economic importance for their meat and in the caviar industry as well as habitat destruction of their spawning grounds. Sturgeons are represented by two large groups of species with different chromosome numbers based on karyological investigations of Acipenserid fishes. The lowchromosome numbered species are traditionally categorised into two subgroups, the genus Huso (two species) and Acipenser (17 species). However, several molecular studies have revealed a more complex systematic relationship that Huso is not a separate genus from Acipenser within the Acipenserinae (Birstein and de Salle, 1998; Tagliavini et al., 2007; Ruiz-Rejón et al., 2000). Furthermore, craniological characteristics (Vasil'eva, 2009) also grouped Huso within Acipenser.
The taxonomic status of the Persian, $A$. persicus and Russian, A. gueldenstaedtii has been of much controversy and debate since the 1930s (Vasil'eva, 2009). The Persian sturgeon $A$. persicus was first described as a valid species from the Ural River but have gone through many taxonomic revisions in relation to its taxonomic status to A. gueldenstaedtii (Ruban et al., 2008) as a subspecies of $A$. gueldenstaedtii, a different race or biological group as according to divisions of spawning seasons.

The debate gained greater impetus when mitochondrial marker analysis was shown not to concur with morphological delineation of discrete taxonomic groups.

Since then the polyphyletic nature of $A$. gueldenstaedtii with respect to $A$. persicus and two other sturgeon species based on mitochondrial markers has been well documented (Birstein et al., 2000; Ruban et al., 2008). The phylogenetic analysis conducted by Birstein et al. (2000) on a $2.3 \mathrm{~kb}$ of mtDNA sequence data (cytochrome b, NADH5, control region) separated $A$. gueldenstaedtii into two distinct clades. One

Corresponding Author: M.N. Siti Azizah, School of Biological Sciences, University Sains Malaysia, Penang, Malaysia 
A. gueldenstaedtii mitochondrial lineage comprised of $A$. persicus and $A$. naccarii, whereas the other one was more closely related to $A$. baerii. More recently (Ruban et al., 2008) combined results of 28 morphometric, 6 meristic characters and the complete cytochrome $\mathrm{b}$ did not support the validity of the Persian sturgeon as a separate species from the Russian sturgeon. However, craniological indices demonstrated that these two could be differentiated (Vasil'eva, 2009).

The importance of DNA barcoding (Hebert et al., 2003 ) in the various fields of biology, management and conservation has gained much attention in the past few years (Armstrong and Ball, 2005; Savolainen et al., 2005). The barcode region comprising of a $650 \mathrm{bp}$ segment of the 5 'end of Cytochrome Oxidase I (COI) gene is now becoming the focus for species identification of fishes (Ward et al., 2005; Rock et al., 2008). Smith et al. (2008) opined that this approach is expected to become a standard tool for recognition of fish specimens. Thus the main objective of this investigation was to obtain unambiguous identification of the sturgeon species in the southern Caspian Sea and contribute towards the global effort of a standardized reference sequenced library for all fish species. In particular, we seek to clarify through this marker, ambiguities between the Russian and Persian sturgeon. However, with the inclusion of several sequences from the Genbank database we also aimed to explore phylogenetic insights of the five species of the southern Caspian Sea.

\section{MATERIALS AND METHODS}

Individuals of the five sturgeon species namely A. gueldenstaedtii (Russian sturgeon), A. persicus (Persian sturgeon), A. stellatus (Stellate sturgeon), A. nudiventris (Spiny sturgeon) and $H$. huso (Great sturgeon) were sampled from the Iranian waters of the Southern Caspian Sea. DNA was extracted from fin clips of five individuals of each species using Genispin ${ }^{\mathrm{TM}}$ Tissue DNA Kit (BST Tech Laboratory) or AquaGenomic ${ }^{\mathrm{TM}}$ DNA isolation Kit following the manufacturer's manual. The primer pair LCO1490 (5'GGTCAACAAATCATAAAGATATTGG-3') and HCO2198 (5'-TAAACTTCAGGGTGACCAAAAAATCA3') was utilized to amplify partial Cytochrome Oxidase subunit I (COI) gene (Folmer et al., 1994).

Amplification reactions were performed in a PTC200, Peltier Thermal Cycler (MJ Research) in a total of $25 \mu \mathrm{L}$ containing $19.325 \mu \mathrm{L}$ sterile distilled $\mathrm{H}_{2} \mathrm{O}, 2.25 \mu \mathrm{L}$ 10X PCR buffer, $1.20 \mu \mathrm{L}$ of $25 \mathrm{mM} \mathrm{MgCl}_{2}, 0.125 \mu \mathrm{L}$ of $10 \mu \mathrm{M}$ dNTPs, $0.25 \mu \mathrm{L}$ of each $5 \mathrm{pM}$ primers (forward Primer; LCO1490 and Reverse Primer; HCO2198), $0.1 \mu \mathrm{L}$
5U Taq DNA polymerase and $1.5 \mu \mathrm{L}$ of DNA template. Control reaction, containing all components except genomic DNA was included in every set of amplification reaction.

PCR reaction protocol was as the following: Predenaturation at $94^{\circ} \mathrm{C}$ for $1 \mathrm{~min}$ followed by denaturation at $94^{\circ} \mathrm{C}$ for $30 \mathrm{sec}$ (repeated for 5 cycles), annealing at $45^{\circ} \mathrm{C}$ for $1.30 \mathrm{~min}$ extension at $72^{\circ} \mathrm{C}$ for $1 \mathrm{~min}$, denaturation at $94^{\circ} \mathrm{C}$ for $30 \mathrm{sec}$, annealing at $51^{\circ} \mathrm{C}$ for $1.30 \mathrm{~min}$ (repeated for 35 cycles), extension at $72^{\circ} \mathrm{C}$ for $1 \mathrm{~min}$ and final extension at $72^{\circ} \mathrm{C}$ for $5 \mathrm{~min}$. PCR products were purified using QIA quick PCR purification kit (Qiagen) following the manufacturer's manual followed by automated DNA sequencing (ABI PRISM 377 DNA sequencer). Sequences were edited, aligned and analysed using MEGA version 4 (Tamura et al., 2007). Divergences were calculated based on the Kimura two-parameter (K2P) distance model (Kimura, 1980). Phylogenetic relationships were examined using Neighbor-Joining (NJ) and Maximum Parsimony (MP). For the NJ tree, robustness was assessed by 1000 bootstrap replicates and MP tree robustness was assessed by 500 bootstrap replicates. An additional 10 sequences from the Genbank were included in the analysis; A. stellatus (AJ585050), H. huso (AY442351) A. baerii (FJ205560FJ205563), A. fulvescens (EU524397), A. transmontanus (EU523891), A. medirostris (EU523885) and $A$. oxynrinchus (EU524401).

\section{RESULTS}

Sequence variation: A total of 631 bp partial sequence of the mtDNA COI gene was sequenced from 25 samples of five sturgeon species. All studied sequences have been deposited and are available in GenBank with accession numbers FJ809715-FJ809739. Both topologies (Fig. 1 and 2) revealed similar topologies with slightly higher resolution in the NJ analysis. Three of the investigated species namely $A$. nudiventris, A. stellatus and $H$. huso formed a monophyletic assemblage confirming their taxonomic identification using the barcoding gene of COI. However, haplotypes of $A$. persicus and the Genbank sequences of $A$. baeri interspersed with $A$. gueldenstaedtii assorting into two major and distinct well supported clades. One A. gueldenstaedtii mitochondrial lineage is interspersed with mainly $A$. persicus, while the other is more closely related to $A$. baerii. The Genbank sequences of Acipenser transmontanus and $A$. medirostris formed another clade with $A$. oxyrhinchus as a sister taxon but with low confidence. However, detailed interspecies relationships 


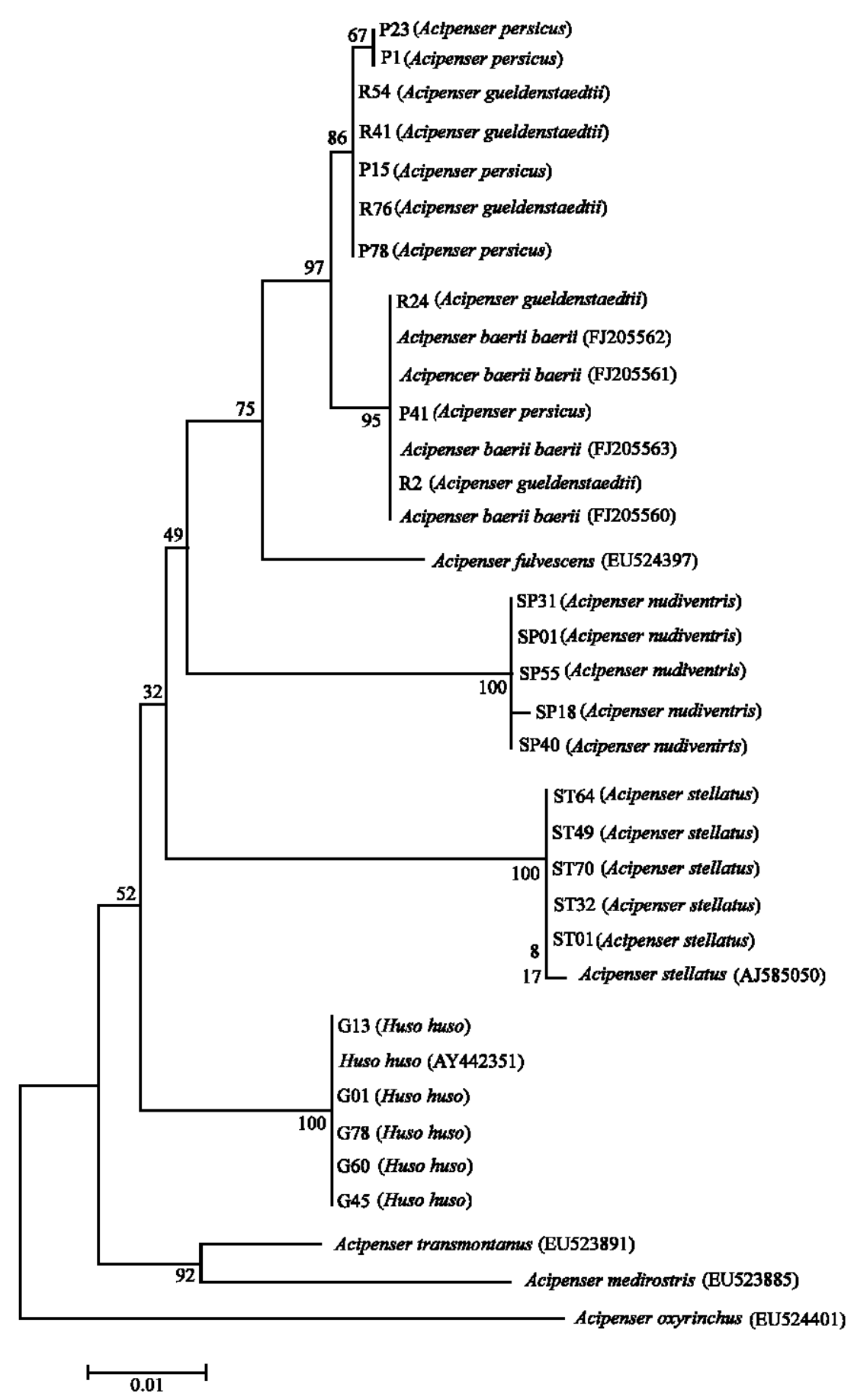

Fig. 1: Dendogram generated through NJ method showing phylogenetic relationships among sturgeon species. Values at nodes represent bootstrap confidence level (1000 replicates)

were not informative due to the associated low confidence although the data separated the $A$. gueldenstaedtii, $A$. persicus and A. baeri (FJ205560-FJ205563) into one cluster, while A. fulvescens (EU524397), A. nudiventris, A. stellatus, H. huso, A. transmontanus (EU523891), A. medirostris (EU523885) and A. oxynrinchus (EU524401) in another with 75 and 69\% support in the NJ and MP analysis, respectively. Phylogenetic relationships within the second cluster could not be determined due to the low branch support. Interesetingly, $H$. huso was embedded among the Acipenser species and did not form the basal clade as would be expected of a different genus. 


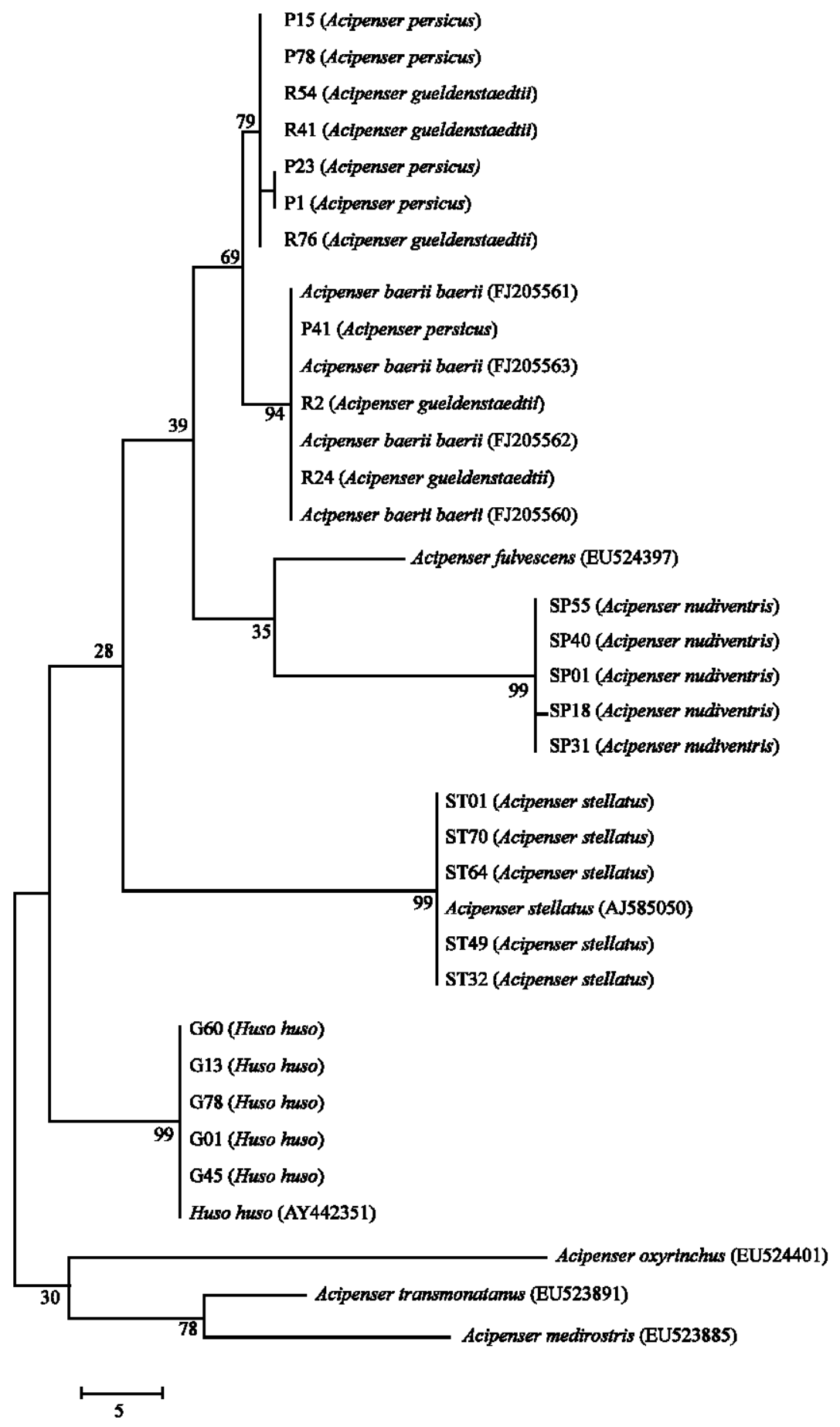

Fig. 2: Dendogram generated through MP method showing phylogenetic relationship among sturgeon species. Values at nodes represent bootstrap confidence level (500 replicates)

\section{DISCUSSION}

This study confirms the utilization of the COI barcoding gene for diagnosis of three southern Caspian
Sea sturgeons namely $H$. huso, A. nudiventris and A. stellatus through their monophyly. However, the data failed to resolve the taxonomic status of A. gueldenstaedtii and $A$. persicus. The COI barcoding 
gene has been successfully utilized in a vast range of organisms ranging from insects (Smith et al., 2005; Janzen et al., 2005) to fishes (Ward et al., 2005; Rock et al., 2008) and extinct ratite birds, the moa of New Zealand (Lambert et al., 2005). However, even within these studies, ambiguities in several taxonomic groups were detected. As suggested by Rock et al. (2008) in their investigation of the Scotia Sea fishes, failure to discriminate taxonomic groups may reflect shared haplotypes possibly representing previous introgressive hybridization between species with overlapping ranges. In cases, where this marker set lacked sensitivity then other markers (Savolainen et al., 2005; Monaghan et al., 2005) should be utilized as set out in the barcoding guidelines in Consortium of Barcode of Life, CBOL (http://barcoding.si.edu/).

In a recent publication, Rach et al. (2008) discussed the pitfalls in relying on phenetic approaches and treebuilding methods for defining species boundaries due to the difficulties in determining a universal threshold of genetic distance values to distinguish taxonomic groups. They suggested DNA barcoding approaches of character based, whereby species are identified through the presence or absence of discrete nucleotide substitutions (character states) within a DNA sequence as another alternative. Their investigation demonstrated the potential of using this technique not only to delineate species within this group but also population level differentiation. A total of 54 species and 22 genera of Odonata were discriminated through unique combinations of character states within only a single mitochondrial non $\mathrm{COI}$ gene region (NADH dehydrogenase 1). Thus, this could be a future useful option to address the complex status of A. gueldenstaedtii group. Needless to add, distinguishing between these species is vital as they are endangered and is subject to a high degree of commercial exploitation (Birstein et al., 2000).

Beluga sturgeon, $H$. huso and its close relative the kaluga sturgeon $H$. dauricus have been traditionally considered as representatives of a separate genus Huso within the subfamily Acipenserinae of the family Acipenseridae based on morphological studies (Bemis et al., 1997). However, since the mtDNA studies of Birstein et al. (1997) and Birstein and de Salle (1998), there has been accumulating evidence of Huso being synonymous with Acipenser within the Acipenserinae. Similarly in this study, the clustering of $H$. huso within the Acipenser clade of the four investigated species and additional Genbank data of Acipenser species is in agreement with this. As pointed out by Tagliavini et al. (2007) based on their investigations of the cytochrome b (cyt b) gene, the generic status of the Huso within
Acipenserinae should be reviewed, a view supported by this data. Although, phylogenetic relationships insights may be obtained from barcoding studies (Ward et al., 2005), the investigations highlights the limitations of this short fragment of the COI in inferring phylogenetic relationships among the Acipenser genus. This is perhaps due to the more conserved amino acid sequence within the COI gene in the Acipenser relative to other taxonomic groups where phylogenetic relationships have been deduced. Other phylogenetic analyses using longer length sequences or combined markers have been more efficient in resolving the phylogenetic relationships of this group (Birstein and de Salle, 1998; Tagliavini et al., 2007 ) and is definitely a more useful approach.

\section{CONCLUSION}

This study confirms the utility of the COI barcoding gene in accurate identification on three of the five sturgeon species in the southern Caspian Sea but has yet again failed to resolve the $A$. gueldenstaedtii-A. persicus controversy based on distance methods of single mtDNA.

\section{RECOMMENDATIONS}

It is suggested that future studies should incorporate character-based methods. In addition, the data supports the view that $H$. huso may not be a separate genus from Acipenser within the Acipenserinae.

\section{ACKNOWLEDGEMENTS}

We would like to thank the Golestan Fisheries Research Center (GFRC), Iran, School of Biological Sciences, Universiti Sains Malaysia, Malaysia and all individuals that were directly or indirectly involved in this resaerch.

\section{REFERENCES}

Armstrong, K.F. and S.L. Ball, 2005. DNA barcodes for biosecurity: Invasive species identification. Philos. Trans. R. Soc. B, 360: 1813-1823.

Bemis, W.E., E.K. Findeis and L. Grande, 1997. An overview of Acipenseriformes. Environ. Biol. Fish., 48: 25-71.

Birstein, V.J. and R. de Salle, 1998. Molecular phylogeny of Acipenserinae. Mol. Phylogenet. Evol., 9: 141-155.

Birstein, V.J., P. Doukakis and R. de Salle, 2000. Polyphyly of mtDNA lineages in the Russian sturgeon, Acipenser gueldenstaedtii: Forensic and evolutionary implications. Conserv. Genet., 1: 81-88. 
Birstein, V.J., R. Hanner and R. de Salle, 1997. Phylogeny of the Acipenseriformes: Cytogenetic and molecular approaches. Environ. Biol. Fish., 48: 127-155.

Folmer, O., M. Black, W. Hoeh, R. Lutz and R. Vriejenhoek, 1994. DNA primers for amplification of mitochondrial cytochrome c oxidase subunit I from diverse metazoan invertebrates. Mol. Mar. Biol. Biotechnol., 3: 294-299.

Ghadirnejad, H., B. Zhu and J. Chang, 2008. Study on the population genetics of the great sturgeon (Huso huso) in the Southern part of the Caspian Sea using microsatellite loci. J. Applied Biol. Sci., 2: 93-97.

Hebert, P.D.N., A. Cywinska, S.L. Ball and J.R. de Waard, 2003. Biological identifications through DNA barcodes. Proc. R. Soc. Lond. B, 270: 313-321.

Janzen, D.H., M. Hajibabaei, J.M. Burns, W. Hallwachs, E. Remigio and P.D.N. Hebert, 2005. Wedding biodiversity inventory of a large and complex Lepidoptera fauna with DNA barcoding. Philos Trans. R. Soc. B, 360: 1835-1845.

Kimura, M., 1980. A simple method for estimating evolutionary rates of base substitutions through comparative studies of nucleotide sequences. J. Mol. Evol., 16: 111-120.

Lambert, D.M., A. Baker, I. Huynen, O. Haddrath, P.D.N. Hebert and C.D. Millar, 2005. Is a large-scale DNA-based inventory of ancient life possible? J. Heredity, 96: 279-284.

Monaghan, M.T., M. Balke, T.R. Gregory and A.P. Vogler, 2005. DNA-based species delineation in tropical beetles using mitochondrial and nuclear markers. Philos Trans. R. Soc. Lond B Biol. Sci., 360: 1925-1933.

Rach, J., R. de Salle, I.N. Sarkar, B. Schierwater and H. Hadrys, 2008. Character-based DNA barcoding allows discrimination of genera, species and populations in Odonata. Proc. Biol. Sci., 275: 237-247.

Rock, J., F.O. Costa, D.I. Walker, A.W. North, W.F. Hutchinson and G.R. Carvalho, 2008. DNA barcodes of fish of the Scotia Sea, Antarctica indicate priority groups for taxonomic and systematics focus. Antarctic Sci., 20: 253-262.

Rosenthal, H., M. Pourkazemi and R. Bruch, 2006. The 5th international symposium on sturgeons: A conference with major emphasis on conservation, environmental mitigation and sustainable use of the sturgeon resources. J. Appl. Ichthyol., 22: 1-1.
Ruban, G.I., M.V. Kholodova, V.A. Kalmykov and P.A. Sorokin, 2008. Morphological and molecular genetic study of the persian sturgeon Acipenser persicus borodin (acipenseridae) taxonomic status. J. Ichthyol., 48: 891-903.

Ruiz-Rejón, M., R. de la Herrán, C. Ruiz-Rejón and M.A. Garrido-Ramos, 2000. Genetic characterization of Acipenser sturio L., 1758 in relation to other sturgeon species using satellite DNA. Boletin Instituto Espanol Oceanografia, 16: 231-236.

Savolainen, V., R.S. Cowan, A.P. Vogler, G.K. Roderick and R. Lane, 2005. Towards writing the encyclopaedia of life: An introduction to DNA barcoding. Philos Trans. R. Soc. Lond B Biol. Sci., 360: 1805-1811.

Smith, M.A., B.L. Fisher and P.D.N. Hebert, 2005. DNA barcoding for effective biodiversity assessment of a hyperdiverse arthropod group: The ants of Madagascar. Philos Trans. R. Soc. Lond B Biol. Sci., 360: 1825-1834.

Smith, P.J., S.M. Mcveagh and D. Steinke, 2008. DNA barcoding for the identification of smoked fish products. J. Fish Biol., 72: 464-471.

Tagliavini, J., F. Conterio, G. Gandolf and F. Fontana, 2007. Mitochondrial DNA sequences of six sturgeon species and phylogenetic relationships within Acipenseridae. J. Applied Ichthyol., 15: 17-22.

Tamura, K., J. Dudley, M. Nei and S. Kumar, 2007. MEGA4: Molecular evolutionary genetics analysis (MEGA) software version 4.0. Mol. Biol. Evol., 24: 1596-1599.

Vasil'eva, E.D., 2009. Morphological and Morphometric Characters in Sturgeon Taxonomy and Phylogeny. In: Chapter 3, Biology, Conservation and Sustainable Development of Sturgeons, Carmona, R. (Ed.). Springer Science, USA., pp: 51-61.

Ward, R.D., T.S. Zemlak, H.I. Bronwyn, R.L. Peter and P.D.N. Hebert, 2005. DNA barcoding Australia's fish species. Philos Trans. R. Soc. Lond B Biol. Sci., 360: 1847-1857. 